\title{
Optical enhancement of phosphor-converted wLEDs using glass beads
}

\author{
Tuğrul Güner, Ufuk Şentürk, Mustafa M. Demir \\ Department of Materials Science and Engineering, Izmir Institute of Technology, Izmir, Turkey
}

\section{A $\quad$ R $T$ T I C C L E I I N F O}

\section{Article history:}

Received 19 May 2017

Received in revised form

28 June 2017

Accepted 16 July 2017

Available online 21 July 2017

Keywords:

Phosphor converted w-LED

PDMS

Remote phosphor

Spray coating

White light

YAG: $\mathrm{Ce}^{3+}$

\begin{abstract}
A B S T R A C T
YAG: $\mathrm{Ce}^{3+}$ is a yellow-source compound commonly used in phosphor conversion layers for direct coating or remote phosphor configurations in LED illumination. This material, however, suffers from a high correlated color temperature, and low color-rendering index due to its deficiency in the red spectrum. In this study, glass beads (GB) with an average particle diameter of $10 \mu \mathrm{m}$ were introduced to the conversion layer of a YAG: $\mathrm{Ce}^{3+}$ particulate-filled polydimethylsiloxane matrix composite structure and found to improve the optical features of the resulting composite.
\end{abstract}

(c) 2017 Elsevier B.V. All rights reserved.

\section{Introduction}

Phosphor-converted white LEDs [1-5] (pc-wLEDs) are widely used to produce white light of varying color quality and indispensable to the lighting industry because of their low energy consumption. According to the 2016 Solid-State Lighting Forecast Report of the U.S. Department of Energy [6], energy savings of 75\% can be expected by 2035 if the Department of Energy goal of more extensive LED use for lighting is achieved. However, the use of phosphors, which contain rare-earth elements, in LED packages may pose significant challenges in terms of cost and raw material availability. Considering current limitations, any material that can improve the performance of phosphors may be of strong demand in the industry [7].

Approaches such as reducing phosphor content in pc-wLEDs $[8,9]$ and finding phosphor-free conversion materials, including quantum dots [10] and perovskites [11], have been developed. However, attempts to produce significant materials should result in a high color rendering index (CRI), a low correlated color temperature (CCT), high efficacy, and a stable light output without fluctuations under different driving currents. Moreover, the structure of composite coatings, including its homogeneity [12,13] and internal microstructure $[14,15]$, determines the blue light flux in the

\footnotetext{
* Corresponding author.

E-mail address: mdemir@iyte.edu.tr (M.M. Demir).
}

overall spectrum [16], i.e., determines the optical performance of coatings in terms of CCT, CRI, efficacy, luminous flux, and radiant flux. These requirements are the main concerns in producing a commercially viable light source.

CCT is crucial for indoor and outdoor lighting (white) applications. This characteristic is the equivalence of a blackbody radiation at particular temperature with the lighting source in charge in terms of the generated light. Thus, while a low CCT (warm white) is preferred for indoor use to promote relaxation, a high CCT (cool white) is desired for outdoor use, such as in mall centers or traffic lightings, to maintain a more energetic atmosphere. In general, cool white corresponds to CCT values $>5000 \mathrm{~K}$, whereas warm light corresponds to CCT values between 2500 and $5000 \mathrm{~K}$. Luminous efficacy (LEF) is a characteristic that defines the degree of matching between a spectrum and the sensitivity of the human eye [17]. It is defined as

$L E F=683 \operatorname{lm} / W \frac{\int v(\lambda) \varnothing(\lambda) d \lambda}{\int \varnothing(\lambda) d \lambda}$

where $v(\lambda)$ is the luminosity function and $\varnothing(\lambda)$ is the spectral power distribution per wavelength.

In blue LEDs with a yellow phosphor $[1-3,18]$, blue light excites the phosphor particles to produce yellow light, which then combines with blue light to generate white light. Flexible polymer- phosphor composite films have been used with blue LEDs in the form of direct coatings or remote phosphors [4,19-21]. Studies on 
various polymer-phosphor composites for use in solid-state lighting have been reported in the literature $[4,19,22]$; these composites include $\mathrm{CeF}_{3}:\left(\mathrm{Tb}^{3+}, \mathrm{Dy}^{3+}, \mathrm{Eu}^{3+}\right)[23], \mathrm{YVO}_{4}:\left(\mathrm{Eu}^{3+}\right)[24]$, GYAG [25], YAG: $\left(\mathrm{Ce}^{+3}, \mathrm{Gd}^{3+}\right)$ [26], YAG: $\left(\mathrm{Ce}^{+3}\right)$ [4,27-29], $\mathrm{Zn}_{2} \mathrm{SiO}_{4}:\left(\mathrm{Mn}^{2+}, \mathrm{Eu}^{3+}\right)[30], \mathrm{BaIn}_{6} \mathrm{Y}_{2} \mathrm{O}_{13}:\left(\mathrm{Yb}^{3+}, \mathrm{Tm}^{3+}, \mathrm{Er}^{3+}\right)$ [31] particles dispersed in poly(methyl methacrylate), $\mathrm{Na}_{2} \mathrm{SO}_{4}$ [32], $\mathrm{BaAl}_{\mathrm{x}} \mathrm{O}_{\mathrm{y}}:\left(\mathrm{Eu}^{2+}, \mathrm{Dy}^{3+}\right)[33]$ in low-density polyethylene, $\mathrm{YAG}: \mathrm{Ce}^{+3}$ in polydimethylsiloxane (PDMS) [34,35], $\mathrm{YBO}_{3}:\left(\mathrm{Eu}^{2+}\right)$ [36] and YGG: $\left(\mathrm{Tb}^{3+}\right)$ [37] in a polyvinylpyrrolidone matrix, and YAG:Ce ${ }^{3+}$ mixed with melted polycarbonate [38].

In this study, PDMS is used as a binder; this material is inexpensive, hydrophobic, transparent, and flexible due to its $\mathrm{Si}-\mathrm{O}$ bond [39] and has a very high bonding energy (452 kJ/mol) [40], which keeps it from degradation under illumination of the energetic forms of light, such as blue and UV light. Moreover, its viscoelastic behavior and cross-linkable nature make it suitable for application as a coating material for various processes [41]. This study aims to understand the optical effects of glass beads (GB) in a YAG: $\mathrm{Ce}^{3+}$ phosphor containing a polymer composite when used as an optical element in an LED light system.

\section{Experimental}

\subsection{Materials and methods}

Phosphor powders of YAG:Ce $\mathrm{Ce}^{3+}(\mathrm{HB}-4155 \mathrm{H}$, Zhuhai Hanbo Trading Co., Ltd., Guangdong, China) and GB with a refractive index $n=1.51$ at the sodium D line (Spheriglass 5000, Potters Industries LLC, USA) were used as received. Sodium aluminosilicate spheres (Z-Cel, Potters Industries, LLC) with a refractive index $n=1.51$ were also used in this study to enable comparison with GB. PDMS (SYLGARD 184 Kit, Dow Corning, Midland, MI, USA) was used as the polymer matrix, and hexane (>95\%, Sigma-Aldrich, St. Louis, MO, USA) was used to thin the PDMS powder solutions. An X-ray diffractometer (X'Pert Pro, Philips, Eindhoven, The Netherlands) was used to record the diffraction patterns of the phosphor powders, and a fluorescence spectrophotometer (Cary Eclipse, Agilent, Palo Alto, CA, USA) was used to collect photoluminescence (PL) spectra. Particle morphology was determined by scanning electron microscopy (SEM; Quanta 250, FEI, Hillsboro, OR, USA), and emission spectra, CCT, CRI, luminous flux, and radiant flux were determined by an integrating sphere (ISP-50-80-R, Ocean Optics Inc.) connected to a USB2000 + spectrometer (Ocean Optics Inc., Dunedin, FL, USA) via a premium fiber cable.

\subsection{Preparation of the PDMS / (phosphor + glass bead) composite films}

PDMS coatings were prepared on a diffuser polycarbonate (PC) substrate by spray-coating (Mac Allister PLD 3010, $500 \mathrm{~W}$ ); this technique atomizes the given solution or dispersion via high air pressure.

In a typical coating, first PDMS oligomers and a curing agent were prepared at a 10:1 mass ratio in a vial. Then, $0.4 \mathrm{gr} \mathrm{YAG:C \textrm {Ce } ^ { 3 + }}$ and proper amount of GB were added. The amount of inorganic material (GB + phosphor) used ranged from 50\% to 55\% with respect to the solid content (PDMS + GB + phosphor) in the composite. The amounts of GB in the coating materials are reported as GB contents/phosphor amount ratio in terms of mass and ranged between 0.2 and 1.5. For proper spraying, PDMS/(phosphor $+\mathrm{GB})$ dispersions in the vial were thinned by hexane and then mixed by a magnetic stirrer. The dispersions were placed into the hopper of a spray gun with a glass vial (Scheme S1) and then sprayed onto a PC diffuser, which is a square having equal sides of $4 \mathrm{~cm}$. Since phosphor particles are heavier than the GB particles, they sediment faster. To overcome this problem, hopper of the spray gun was shaked periodically during the spraying process. The resulting thicknesses of the YAG: $\mathrm{Ce}^{3+}$ composite coatings ranged from $60 \mu \mathrm{m}$ to $100 \mu \mathrm{m}$ depending on the solid content. Samples were left at room temperature overnight to allow complete evaporation of hexane, after which they were cured at $120^{\circ} \mathrm{C}$ for $1 \mathrm{~h}$ in an oven.

\subsection{Optical measurement}

A remote measurement setup was employed for optical measurements [4,19-21,42]. A fixed distance $(3 \mathrm{~cm})$ was maintained between the film and a blue LED surface in a black chamber. A $455 \mathrm{~nm}$ monochromatic LED light source (Cree, Royal Blue 1W, USA) running at $0.35 \mathrm{~mA}$ input current was used in this configuration.

\section{Results and discussion}

\subsection{Characteristics of YAG:C $\mathrm{e}^{3+}$ and the glass beads}

Fig. 1a shows an SEM image of GB, which appears to present a spherical geometry. The mean particle size of the beads is $5 \mu \mathrm{m}$, as determined from electron micrographs using Image [43]. The inset in the figure shows a magnified image of GB for better visualization of its spherical shape. An SEM image of the yellow phosphor YAG: $\mathrm{Ce}^{3+}$ particles is shown in Fig. 1b. The mean diameter of the phosphor particles is around $3 \mu \mathrm{m}$. Fig. 1c depicts the emission and excitation spectra of the YAG: $\mathrm{Ce}^{3+}$ powder. The emission spectrum shows two absorption bands centered at 340 and $460 \mathrm{~nm}$ $\left(\lambda_{\mathrm{em}}=550 \mathrm{~nm}\right)$. These signals refer to the split $4 \mathrm{f} \rightarrow 5 \mathrm{~d}$ transition states of the dopant $\mathrm{Ce}^{3+}$ in the YAG matrix [44]. The excitation spectrum, where $\lambda_{\mathrm{ex}}=458 \mathrm{~nm}$, shows a broad emission centered at $550 \mathrm{~nm}$. In Fig. 1d, the X-ray diffraction spectrum of the YAG:Ce ${ }^{3+}$ powder matches the crystallographic data of the host material, YAG (Joint Committee on Powder Diffraction Standards Card No.: 01079-1891). A single weak reflection that is not indexed with the crystallographic data is labeled as unidentified.

\subsection{Effect of glass beads on the optical performance of the phosphor layer}

Fig. 2a shows the PL spectra of PDMS coatings containing a constant amount of phosphor and various concentrations of GB. The reference spectrum is obtained from a coating prepared using PDMS and phosphor particles without beads; this coating presents an efficacy of $121 \mathrm{~lm} / \mathrm{W}$, luminous flux of $0.248 \mathrm{~lm}$, and no valid CCT or CRI, which means it does not generate white light.

Unsurprisingly, PDMS coatings containing phosphor particles provide two signals. The first signal lies in the blue region and could be attributed to the photons transmitted through the coating, while the second signal lies in the yellow region and could be attributed to the emission of the YAG: $\mathrm{Ce}^{3+}$ phosphor. The quality of white light in terms of CCT is related to the ratio of these two signals. The phosphor concentration is the most significant parameter influencing the production of white light, and a threshold concentration of yellow phosphor particles should ideally be maintained to produce good-quality light (Fig. S1). A valid CCT for commercial applications appears only at a phosphor/(amount of inorganic material with respect to the solid content) ratio of 1.15 .

In this study, we began with a ratio of 0.77 (Fig. S1), at which point no white light optical feature is found upon illumination of the coating with blue light. This result can be attributed to the lack of a yellow flux region in the coating. Addition of small amounts of GB to the PDMS + YAG:Ce ${ }^{3+}$ system, as shown in Fig. $2 a$, causes the shape of the spectrum to remain unchanged, i.e., two signals 


\section{a)}

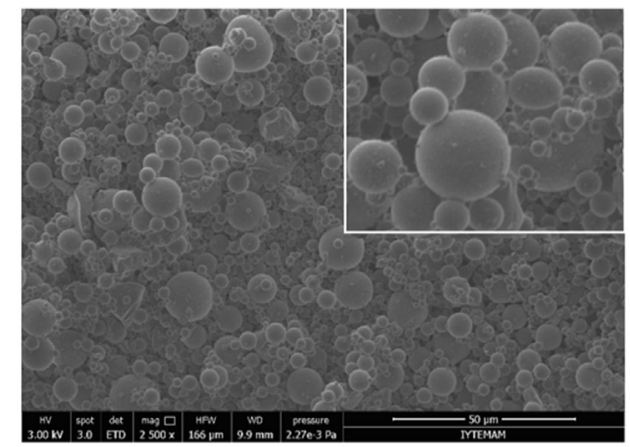

C)

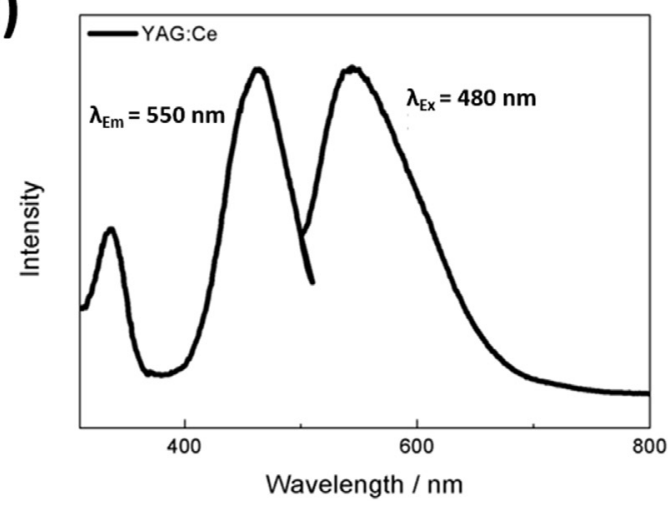

b)

\section{YAG:Ce ${ }^{3+}$}

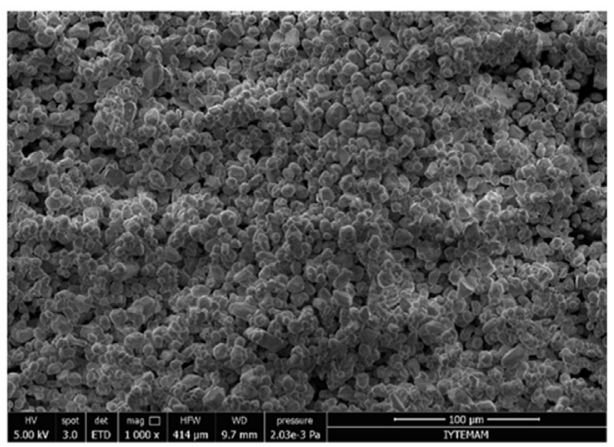

d)

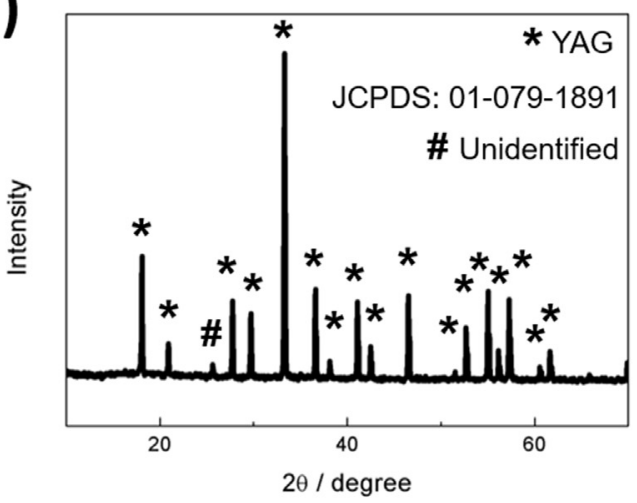

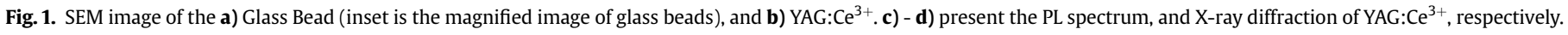

appearing in the blue and yellow regions are still observed. However, the ratio of these signals varies such that the transmission of blue light from the PDMS coating decreases (7\%) while its yellow emission is maintained. The presence of GB can lead to a bluesignal reduction of nearly $71 \%$ and a simultaneous increase in yellow light emission of $20 \%$ at a GB/phosphor ratio of 1.5 . Fig. 2 b shows the CIE 1931 color coordinates of these samples. Phosphor reference shows an explicit blue color while it changes towards warm white color with the addition of glass beads. In Fig. 3a, photograph of both phosphor reference, and phosphor + GB coating at $(\mathrm{GB} /$ phosphor) mass ratio at 1.5 is given. The difference is that phosphor + GB sample has slightly more intensive yellow appearance than the phosphor reference. The effect of addition of GB to the coating on the white light generated can be observed explicitly in Fig. 3b-c. In Fig. 3b, differences between the phosphor and phosphor + GB coatings are shown photographically; here, samples are illuminated with a blue LED under a driving current of $0.35 \mathrm{~mA}$. A highly bluish light is observed from the phosphor-only coating; this light not as blue as the LED light, but it cannot be considered a useful bluish white because it presents no valid CCT or CRI. In the presence of GB at a ratio of 1.5 , a warm white light is observed. The CCT and CRI of this coating change from "not valid" to $6300 \mathrm{~K}$ and 83, respectively (Fig. 3c). An efficacy of $197 \mathrm{~lm} / \mathrm{W}$, indicating a significant improvement of $63 \%$, is also observed. In other words, introducing GB to the phosphor system provides a means to achieve a viable and controllable white light source. A comparison of the phosphor-only coating (Phosphor/(amount of inorganic material with respect to the solid content) ratio, 1.15) shown in Fig. S1 with the phosphor + GB coating (GB/phosphor ratio, 1.5); the optical performance of these coatings is nearly identical but the CCT of the phosphor + GB coating is markedly improved. This finding indicates that phosphor consumption may be reduced by about $33 \%$ by introducing GB to the system.

To verify this unique effect of GB, PDMS composites with Z-Cel (Sodium aluminosilicate), which are spherical and opaque particles with an average particle diameter of $2-4 \mu \mathrm{m}$, were prepared. Z-Cel has a refractive index and density similar to those of GB, and its volume fraction and phosphor content in the composite were fixed as identical with the GB/phosphor ratio of 1.5 . The main difference between them is, Z-Cel is having a crystalline structure while GB is amorphous. Fig. 4a shows the overall spectrum of the phosphor + Z-Cel coating. While the presence of Z-Cel can reduce the amount of blue light emitted, it cannot enhance the yellow flux region. The CCT values of the phosphor $+\mathrm{Z}-\mathrm{Cel}$ and phosphor $+\mathrm{GB}$ coatings were 5100 and $6300 \mathrm{~K}$, respectively. However, the CRI of the phosphor $+\mathrm{Z}$-Cel coating was 78 in comparison with the 83 of the phosphor $+\mathrm{GB}$ coating. Reducing the blue region alone can lead to tuning of the CCT; however, since no enhancement in the yellow flux region is observed, the phosphor $+\mathrm{Z}$-Cel coating may be expected to show no improvement in luminous flux.

Fig. 4b shows the radiant power and luminous flux of the coatings. The luminous flux of the phosphor $+\mathrm{Z}$-Cel coating is decreased (verifying the statement above) while that of the phosphor + GB coating shows improvement compared with the phosphor reference. This result indicates that light quality becomes poorer in terms of human vision when Z-Cel is used. Moreover, the phosphor + Z-Cel coating traps blue light more by increasing the total path length of the blue light, which means that it takes more time for blue light to escape from the coating. This increase is evidenced by a decrease in the radiant powers given in Fig. $4 \mathrm{~b}$; it is the highest for phosphor + Z-Cel compared to both phosphor reference and phosphor + glass bead samples. While CCT was 
a)

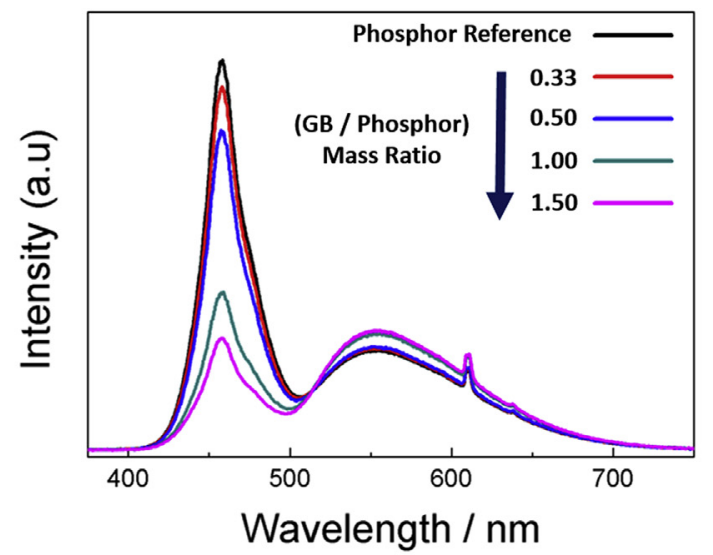

b)

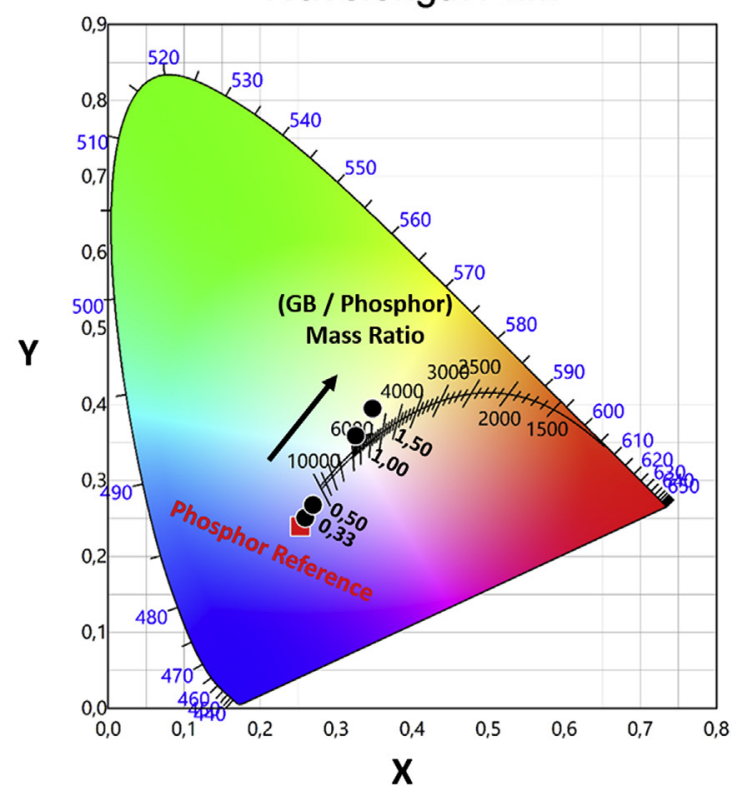

Fig. 2. a) PL spectra of the coatings at fixed phosphor with GB at various contents. Phosphor Reference represents the phosphor-only coating, and b) the CIE 1931 color coordinates of these samples. (For interpretation of the references to colour in this figure legend, the reader is referred to the web version of this article.)

reduced significantly in the presence of Z-Cel, other optical performance parameters for instance CRI, luminous flux, and radiant power are noticeably decreased.

Increasing the GB or any scatterer content in the coatings shortens the transport mean free path [45], which is the average distance the photons travel between two successive interactions between either phosphor and GB particles or GB and GB particles, and increases the multiple scattering of light within the coating volume. Blue light gets trapped more inside the coating volume since it scatters more extensively than yellow light $[45,46]$. Therefore, a decrease in the blue light flux region takes place. This result is typically observed in both GB and Z-Cel, and the effect of this trapping in terms of reduction in the blue light is shown for either cases in Figs. 2a and 4a. Reducing the transmitted blue light from the sample via increasing the multiple scattering of light within the coating therefore requires no any specialty: it may work for any scatterer particles. However, Fig. 2 experimentally demonstrates that increasing the GB content of the coatings uniquely enhances the yellow flux region (which is not observed in the composite containing Z-Cel). This enhancement can be related to the difference between Z-Cel and GB in terms of their interaction with light; Z-Cel shows very high scattering behavior because of its a)

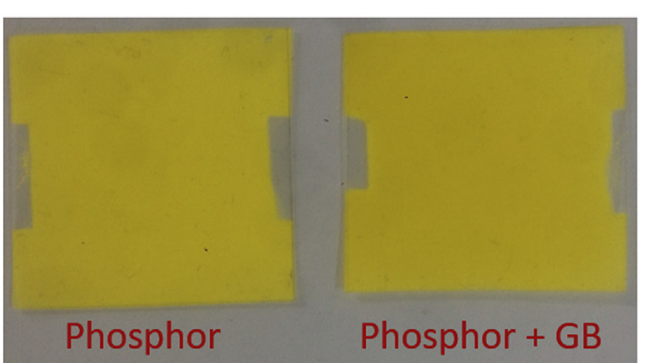

b)
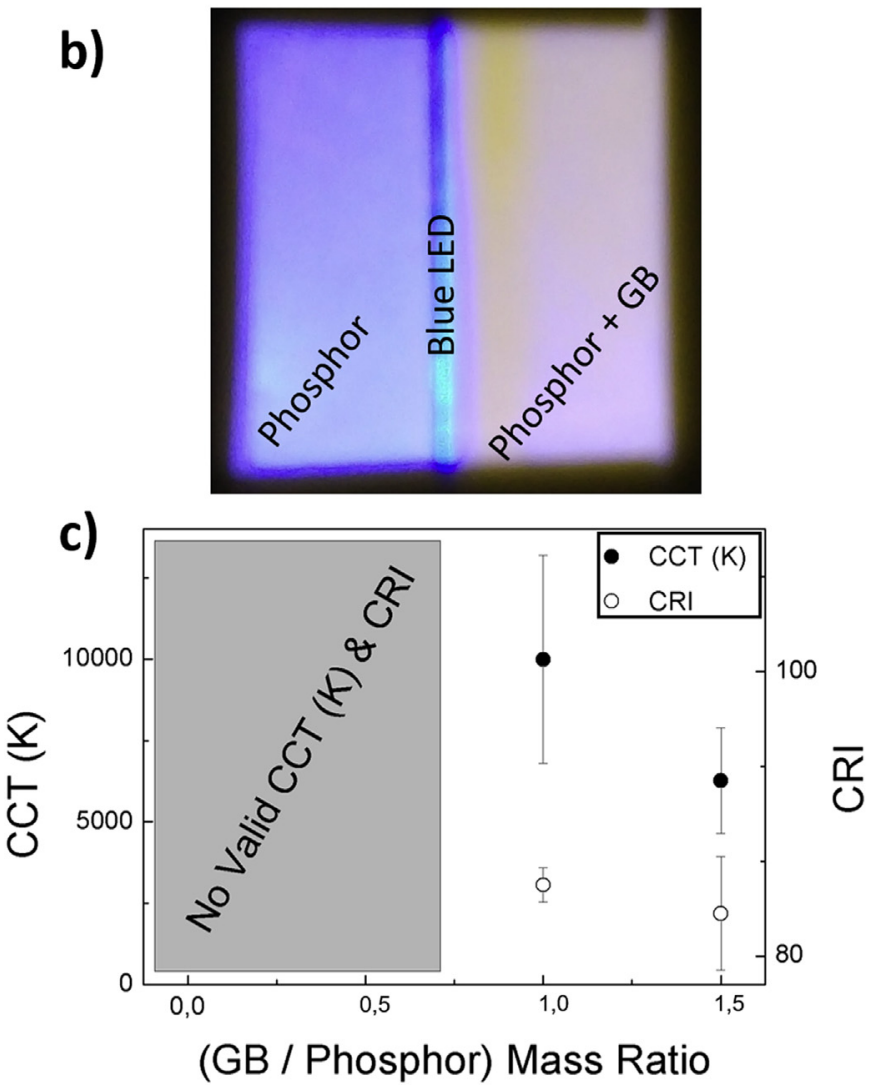

Fig. 3. a) Appearance of the samples; phosphor-only coating and phosphor + GB (at the ratio 1.5), b) Photograph of the generated white light from the phosphor-only coating, and the phosphor + GB (at the ratio 1.5) coating under blue LED illumination with the driving current $0.35 \mathrm{~mA} \mathrm{c}$ ) CCT, and CRI versus $\mathrm{GB} /$ phosphor mass ratio. Boundary between "No valid CCT (K) \& CRI" and valid region represents the amount that phosphor-only coating requires for generating useful white light. (For interpretation of the references to colour in this figure legend, the reader is referred to the web version of this article.)

crystallinity while glass bead can behave similar to a lens. In this sense, in addition to scattering of blue light, GB can show focusing, secondary reflections, and also may cause extra total internal reflections. Therefore, while both samples show reduction of blue light due to multiple scattering of light, it is assumed that the above difference between Z-Cel (as ordinary scatterer) and GB in terms of their blue light interaction is responsible from the enhancement of the yellow flux region.

\section{Conclusion}

In this work, phosphor + GB coatings with varying GB contents were prepared, and the effect of GB on the optical features of the coatings was examined. Addition of GB as an optical element improved the CCT, CRI, and efficacy of the resulting coatings, and 
a)

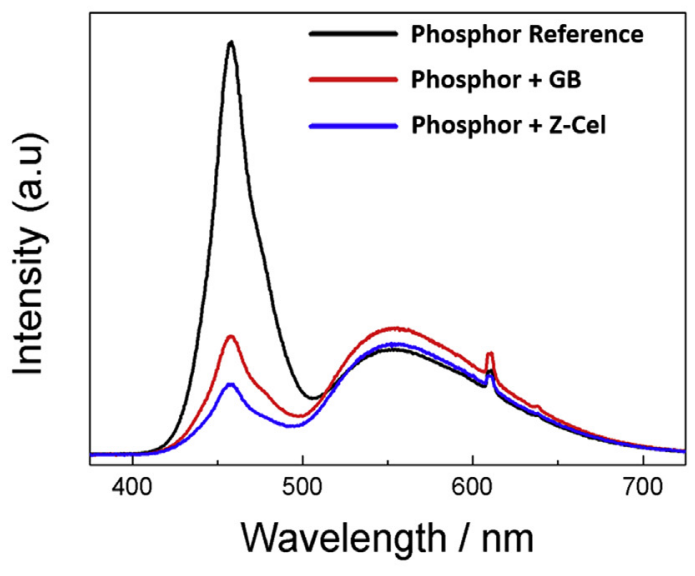

b)

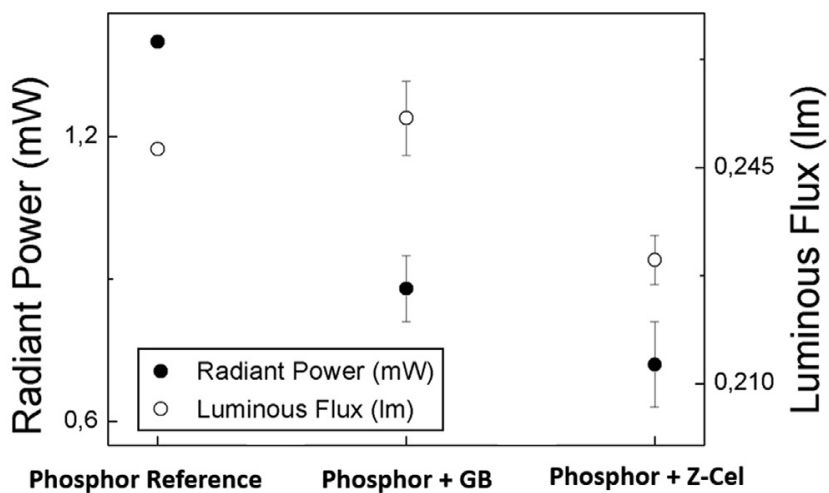

Fig. 4. Comparison of phosphor $+\mathrm{GB}$ coating with a phosphor $+\mathrm{Z}$-Cel in terms of their a) spectra, and b) radiant power and luminous flux. Phosphor Reference represents the phosphor-only coating.

the possible reasons behind these improvements were discussed. Phosphor consumption could be reduced by nearly $33 \%$ by addition of GB (in this study, it is obtained at the particular GB/phosphor mass ratio of 1.5). These findings could be extended to a number of optical systems, such as afterglow materials, solar cells, and other lighting applications.

\section{Author contributions}

The manuscript was written through contributions of all authors. All authors have given approval to the final version of the manuscript.

\section{Acknowledgments}

This work was supported by both "Outstanding Young Investigator" grant of the Turkish Academy of Sciences (TÜBA-GEBIP 2013).

\section{Abbreviations}

PDMS Polydimethylsiloxane

CCT Correlated Color Temperature

CRI Color Rendering Index

YAG: $\mathrm{Ce}^{+3}$ Cerium doped Yttrium Aluminum Garnet

GB Glass Bead

\section{Appendix A. Supplementary data}

Supplementary data related to this article can be found at http:// dx.doi.org/10.1016/j.optmat.2017.07.033.

\section{References}

[1] N.C. George, K.A. Denault, R. Seshadri, Phosphors for solid-state white lighting, Annu. Rev. Mater. Res. 43 (2013) 481-501.

[2] C.C. Lin, R.-S. Liu, Advances in phosphors for light-emitting diodes, J. Phys. Chem. Lett. 2 (11) (2011) 1268-1277.

[3] S. Ye, F. Xiao, Y. Pan, Y. Ma, Q. Zhang, Phosphors in phosphor-converted white light-emitting diodes: recent advances in materials, techniques and properties, Mater. Sci. Eng. R Rep. 71 (1) (2010) 1-34.

[4] S.C. Allen, A.J. Steckl, A nearly ideal phosphor-converted white light-emitting diode, Appl. Phys. Lett. 92 (14) (2008) 143309.

[5] J. McKittrick, L.E. Shea-Rohwer, Review: down conversion materials for solidstate lighting, J. Am. Ceram. Soc. 97 (5) (2014) 1327-1352.

[6] https://energy.gov/eere/ssl/ssl-forecast-report.

[7] C.-F. Lai, J.-S. Li, C.-W. Shen, High-Efficiency robust free-standing composited phosphor films with 2D and 3D nanostructures for high-power remote white LEDs, ACS Appl. Mater. Interfaces 9 (5) (2017) 4851-4859.

[8] T. Ogi, A.B.D. Nandiyanto, K. Okino, F. Iskandar, W.-N. Wang, E. Tanabe, K. Okuyama, Towards better phosphor design: effect of sio2 nanoparticles on photoluminescence enhancement of yag: ce, ECS J. Solid State Sci. Technol. 2 (5) (2013) R91-R95.

[9] C.-C. Tsai, C.-F. Yue, W.-C. Cheng, S.-S. Hu, Y.-C. Hsu, J.-S. Liao, W.-H. Cheng, Performance enhancement of high-temperature glass-based phosphorconverted white light-emitting diodes employing SiO2, SPIE OPTO, Int. Soc. Opt. Photon. (2013), 86411T-86411T-7.

[10] T. Erdem, H.V. Demir, Color science of nanocrystal quantum dots for lighting and displays, Nanophotonics 2 (1) (2013) 57-81.

[11] L. Protesescu, S. Yakunin, M.I. Bodnarchuk, F. Krieg, R. Caputo, C.H. Hendon, R.X. Yang, A. Walsh, M.V. Kovalenko, Nanocrystals of cesium lead halide perovskites ( $\mathrm{Cs} \mathrm{PbX} 3, \mathrm{X}=\mathrm{Cl}, \mathrm{Br}$, and $\mathrm{I}$ ): novel optoelectronic materials showing bright emission with wide color gamut, Nano Lett. 15 (6) (2015) 3692-3696.

[12] C. Sommer, F. Reil, J.R. Krenn, P. Hartmann, P. Pachler, S. Tasch, F.P. Wenzl, The impact of inhomogeneities in the phosphor distribution on the device performance of phosphor-converted high-power white LED light sources, J. Light. Technol. 28 (22) (2010) 3226-3232.

[13] R. Hu, X. Luo, H. Feng, S. Liu, Effect of phosphor settling on the optical performance of phosphor-converted white light-emitting diode, J. Lumin. 132 (5) (2012) 1252-1256

[14] M.M. Demir, P. Castignolles, Ü. Akbey, G. Wegner, In-situ bulk polymerization of dilute particle/MMA dispersions, Macromolecules 40 (12) (2007) 4190-4198.

[15] M.M. Demir, M. Memesa, P. Castignolles, G. Wegner, PMMA/Zinc oxide nanocomposites prepared by in-situ bulk polymerization, Macromol. Rapid Commun. 27 (10) (2006) 763-770.

[16] T. Güner, D. Köseoğlu, M.M. Demir, Multilayer design of hybrid phosphor film for application in LEDs, Opt. Mater. 60 (2016) 422-430.

[17] T. Erdem, S. Nizamoglu, H.V. Demir, Computational study of power conversion and luminous efficiency performance for semiconductor quantum dot nanophosphors on light-emitting diodes, Opt. Express 20 (3) (2012) 3275-3295.

[18] K. Shinde, S. Dhoble, Europium-activated orthophosphate phosphors for energy-efficient solid-state lighting: a review, Crit. Rev. Solid State Mater. Sci. 39 (6) (2014) 459-479.

[19] N. Narendran, Y. Gu, J. Freyssinier-Nova, Y. Zhu, Extracting phosphorscattered photons to improve white LED efficiency, Phys. Status Solidi (a) 202 (6) (2005) R60-R62.

[20] N.T. Tran, J.P. You, F.G. Shi, Effect of phosphor particle size on luminous efficacy of phosphor-converted white LED, J. Light. Technol. 27 (22) (2009) $5145-5150$.

[21] P. Acuña, S. Leyre, J. Audenaert, Y. Meuret, G. Deconinck, P. Hanselaer, Power and photon budget of a remote phosphor LED module, Opt. Express 22 (104) (2014) A1079-A1092.

[22] Y.H. Song, G.S. Han, E.K. Ji, M.-J. Lee, Y.L. Song, M.K. Jung, B.W. Jeong, H.S. Jung, D.-H. Yoon, The novel design of a remote phosphor ceramic plate for white light generation in high power LEDs, J. Mater. Chem. C 3 (24) (2015) 6148-6152.

[23] F.N. Sayed, V. Grover, K. Dubey, V. Sudarsan, A. Tyagi, Solid state white light emitting systems based on CeF 3: RE 3+ nanoparticles and their composites with polymers, J. Colloid Interface Sci. 353 (2) (2011) 445-453.

[24] D. Hreniak, J. Doskocz, P. GŁuchowski, R. Lisiecki, W. Stręk, N. Vu, D. Loc, T. Anh, M. Bettinelli, A. Speghini, Enhancement of luminescence properties of Eu 3+: YVO 4 in polymeric nanocomposites upon UV excitation, J. Lumin. 131 (3) (2011) 473-476.

[25] D. Bera, S. Maslov, L. Qian, J.S. Yoo, P.H. Holloway, Optimization of the yellow phosphor concentration and layer thickness for down-conversion of blue to white light, J. Disp. Technol. 6 (12) (2010) 645-651.

[26] V. Tucureanu, A. Matei, I. Mihalache, M. Danila, M. Popescu, B. Bita, Synthesis and characterization of YAG: Ce, Gd and YAG: Ce, Gd/PMMA nanocomposites for optoelectronic applications, J. Mater. Sci. 50 (4) (2015) 1883-1890. 
[27] M.L. Saladino, A. Zanotto, D. Chillura Martino, A. Spinella, G. Nasillo, E. Caponetti, Ce: YAG nanoparticles embedded in a PMMA matrix: preparation and characterization, Langmuir 26 (16) (2010) 13442-13449.

[28] M.L. Saladino, D. Chillura Martino, M.A. Floriano, D. Hreniak, L. Marciniak, W. Strek, E. Caponetti, Ce: Y3Al5012-poly (methyl methacrylate) composite for white-light-emitting diodes, J. Phys. Chem. C 118 (17) (2014) 9107-9113.

[29] J. Oliva, E. De la Rosa, L. Diaz-Torres, A. Zakhidov, White light emission from a blue polymer light emitting diode combined with YAG: Ce3+ nanoparticles, Phys. Status Solidi (a) 211 (3) (2014) 651-655.

[30] L. Đačanin, S.R. Lukić, D.M. Petrović, Ž. Antić, R. Krsmanović, M. MarinovićCincović, M.D. Dramićanin, PMMA/Zn2SiO4: Eu3+ (Mn2+) composites: preparation, optical, and thermal properties, J. Mater. Eng. Perform. 21 (7) (2012) 1509-1513.

[31] J. Zhang, Y. Yang, C. Mi, Y. Liu, F. Yu, X. Li, Y. Mai, White up-conversion luminescence power and efficiency in $\mathrm{Yb} 3+-$, Er 3+-and Tm 3+-doped BaIn 6 Y 20 13, Dalton Trans. 44 (3) (2015) 1093-1101.

[32] J. Zhang, A.Z.M.S. Rahman, Y. Li, J. Yang, B. Zhao, E. Lu, P. Zhang, X. Cao, R. Yu, B. Wang, Synthesis and luminescence properties of Sm-doped LDPE-Na 2 SO 4 composite material, Opt. Mater. 36 (2) (2013) 471-475.

[33] D.B. Bem, H.C. Swart, A.S. Luyt, F.B. Dejene, Luminescent properties of longlasting BaAlxOy: Eu2+, Dy3+ nanocomposites, J. Appl. Polym. Sci. 121 (1) (2011) 243-252.

[34] d. A. Esteves, J. Brokken-Zijp, J. Laven, G. de With, Light converter coatings from cross-linked PDMS/particles composite materials, Prog. Org. Coat. 68 (1) (2010) 12-18

[35] d. A. Esteves, J. Brokken-Zijp, J. Laven, H. Huinink, N. Reuvers, M. Van, G. de With, Garnet particles effect on the cross-linking of PDMS and the network structures formed, Polymer 51 (1) (2010) 136-145.

[36] P.-O. Bussière, J. Peyroux, G. Chadeyron, S. Therias, Influence of functional nanoparticles on the photostability of polymer materials: recent progress and further applications, Polym. Degrad. Stab. 98 (12) (2013) 2411-2418.
[37] A. Potdevin, G. Chadeyron, S. Therias, R. Mahiou, Luminescent nanocomposites made of finely dispersed Y3Ga5012: Tb powder in a polymer matrix: promising candidates for optical devices, Langmuir 28 (37) (2012) $13526-13535$.

[38] M.L. Saladino, F. Armetta, M.A. Sibeko, A.S. Luyt, D.F.C. Martino, E. Caponetti Preparation and characterisation of Ce: YAG-polycarbonate composites for white LED, J. Alloys Compd. 664 (2016) 726-731.

[39] M.M. Demir, Y.Z. Menceloglu, B. Erman, Effect of filler amount on thermoelastic properties of poly (dimethylsiloxane) networks, Polymer 46 (12) (2005) 4127-4134.

[40] Zumdahl, S.; Zumdahl, S. Chemistry, 9th AP Edition. Belmont, CA: Brooks/Cole 374.

[41] E. Boyacı, N. Horzum, A. Çă̆ır, M.M. Demir, A.E. Eroğlu, Electrospun aminofunctionalized PDMS as a novel SPME sorbent for the speciation of inorganic and organometallic arsenic species, RSC Adv. 3 (44) (2013) $22261-22268$.

[42] Y. Shuai, N.T. Tran, J.P. You, F.G. Shi, in: Phosphor Size Dependence of Lumen Efficiency and Spatial CCT Uniformity for Typical White LED Emitters, 2012 IEEE 62nd Electronic Components and Technology Conference, IEEE, 2012, pp. 2025-2028.

[43] C.A. Schneider, W.S. Rasband, K.W. Eliceiri, NIH Image to ImageJ: 25 years of image analysis, Nat. Methods 9 (7) (2012) 671-675.

44] O. Tunusoğlu, R. Muñoz-Espí, Ü. Akbey, M.M. Demir, Surfactant-assisted formation of organophilic CeO 2 nanoparticles, Colloids Surfaces A Physicochem. Eng. Aspects 395 (2012) 10-17.

[45] V. Leung, A. Lagendijk, T. Tukker, A. Mosk, W. IJzerman, W. Vos, Interplay between multiple scattering, emission, and absorption of light in the phosphor of a white light-emitting diode, Opt. Express 22 (7) (2014) 8190-8204.

[46] W.L. Vos, T.W. Tukker, A.P. Mosk, A. Lagendijk, W.L. IJzerman, Broadband mean free path of diffuse light in polydisperse ensembles of scatterers for white light-emitting diode lighting, Appl. Opt. 52 (12) (2013) 2602-2609. 